\title{
The inspiration of the Development of Postmodernism for College Student's education administration
}

\author{
Yuexin CUI \\ Dongying Ploytechnic \\ Dongying,Shandong,257091 China
}

\begin{abstract}
Postmodernism was a popular philosophy of cultural trends in Western society in fifties and sixties of the 20th century. It advocates decentralization, emphasizes differences, encourages diversity, respects equal dialogue. Its influence covered over education, culture, society, particularly its education thought poured a fresh wind into the transition period of Chinese higher education, even expanded a new vision in educational management during the transitional period, it will have an important impact to update personnel training concepts for Chinese Universities student workers, innovate ways of working and methods, reconstruct the new harmonious teacher-student relationship.
\end{abstract}

Keywords- Postmodernism, universities, educational management, impact

\section{INTRODUCTION}

The earliest emergence of postmodernism in the United States and Europe was in the sixties of last century, ten years and twenty years later, to the seventies and eighties it covers the entire Western world, which formally created on China and other third world countries, its real influence is from the late 1980 s to the early nineties, postmodernism can be understood as a way of thin king, it can also be understood as a cultural trend, in short, it is very large and comple x system, from art to philosophy, it brings various cultural variety of areas, which teaches people look at things with different visual angle and contains a critique of mainstream consciousness, based on the basic starting point, postmodernism provides a new way to re-examine our medical student education management.

\section{DEFINITION OF POST MODERNISM}

About definition of postmodernism, there are different opinions in theoretical circles, but in general it is a reflection of modernity, questioning and critic ism, the basic theory of characteristics are: First, oppose to rationalism. Here's a rational means of Western culture from the ancient Greek tradition of a mainstream cultural trends, a respected cultural knowledge and rational thought. Rationalism was pushed to the peak with the upsurge of Enlightenment rationalism, the rapid development of science and the great victory of the industrial revolution in modern times. Postmodernism opposites to science supremacy, doubts reason and science can bring freedom and liberation, denies knowledge of the existence and relative stability, denies any rational knowledge and methods, denies law and system, advocate the use of non-rational and rational rule to break position that can not be rational as a universal norm, rational human personality is bound to limit human imagination and creativity, only personal feelings, experiences and imagination is real, is the source of the creation and it opposes to basics. Postmodern thinkers believe that in all ages while thinking, they are all looking for a foundation and starting point to explain everything. Postmodern thinkers believe that there is no eternal question of philosophy and philosophical conversation is a human voice, it focuses on a topic rather than another topic in a period. Against the previous philos ophy relies on a first-principle to introduce all the ways and methods, advocates otherness and uncertainty, replaces certainty with uncertainty and ambiguity, advocates diversity and uncertainty, encourages diverse thinking styles. Third, object to centralism. In terms of its methodology, the basic doctrine is a doctrine of determinis $m$, rather than a multi-determin ism doctrine. In ancient times, the West is naturally centered; during the middle Ages, the West is a God-centered; modern Westerners regarded human being as center of the universe. One of the biggest features of modern western philosophy is lifted human subjectivity, emphasizing the master of the world. Postmodern thinkers oppose to such anthropocentric, that human beings should not be the master of all beings, but by the presence of the decision, people is neighbor of existence, any presence is true that any exist are equal. The approval of postmodern thinkers on the concept of equality and recognition of diverse concepts decided that they respected the decision of the dialogue. They thought that the essence of dialogue is not a view imposed on another view, but to change the arguments on both, and ultimately achieve a new vision. In short, the basic tendency of postmodernism is anti-rational, anti-base, anti-authority and centers advocate diversity, pluralism, tolerance, randomness. Although it is one-sided to promote individual autonomy, exaggerate the role of individual will, and deny everything, deny misconceptions epistemology of dialectical materialism, which brings a lot of negative impact to young college students; but it respects the individual's understanding of the 
subject, calls for human freedom, value and dignity, promote harmony between man and nature, encourages diverse thinking styles, respects equal dialogue and other ideas, this is a positive side which has an important constructive. The negative impact of postmodernism to the students is that it brings them with constructive valuable. What the positive impact and negative impact of postmodernism brought has alerts and implications for strengthening and improving the management of students' education in colleges and universities.

\section{POSITIVE IMPACT OF POST MODERNISM ON UNIVERSITY EDUCATION MANAGEMENT}

\section{A. Make management more emphasis on the differences and diversity among students}

Postmodernism is an advocate of postmodern pluralis $\mathrm{m}$, diversity and ideological doctrine of chance, in this kind of thinking, Student Management Work will be affected from different cultural backgrounds and it no longer blindly train the students follow a standard, but pay more attention to the differences between students, diversity. Therefore, the process of planning college education, teaching Japanese standard formulation, and specific teaching force method design, and educational organizations to build programs appear different from the past, this difference lies mainly in the emphasis on the differences and diversity of students, it hopes the students can have a rich personality, and promotes the development of students' individual characteristics, reflects the humanities of college student education management in the greatest degree.

\section{B. Make management more emphasis on student autonomy and creativity}

In the education of college students under the management of post-modernism, the student's autonomy and creativity got more attention because it stands to stimulate students' thinking skills, and guide students to build the initiative of self-criticism, during the learning process, what students applied to all teaching materials are instructive, as well as questions of diversity and other characteristics, they can help students to construct a self-inquiry-based learning environment and learning mechanism, it is able to highlight student's autonomy to train their creativity.

\section{Make management more emphasis on equality and justice}

Looking at the management of education among college students in the past, we find that the relationship between students and teachers are inequality and usually teachers occupies the absolute dominance, and students are left obedient role, such a management greatly suppress the students, so that students in the teaching process highlights the lack of subjectivity, does not focus on communication and understanding, extreme lack of human nature, severely restricted the students' self-development, postmodernism advocates dialogue and understanding to help students and teachers to establish equality between communication channels, to highlight the justice of teaching, as well as teaching and learning equality, so that the relationship between students and teachers become more harmonious, which is not only conducive to the work of Student Management, and more conducive to students' selfdevelopment.

\section{Regard ideals and beliefs of education as the core, strengthen college students'outlook on life and values education}

Postmodernism is based on the values of the individual values, self occupies a central position in the value of the individual, it is the starting point and destination, the individual is the core of everything. This view led to the extreme individualism of the supremacy of the individual tendencies of university students, so some students change from self-development to solipsism, from self-assertive to make self-inflated. So me of the students misinterpreted the modern concept of freedom from personal view, understood it as a personal subjective arbitrariness in dealing with personal and social relationships, in order to achieve selfworth as a core social behavior, they disregard others and society interests or the interests of others with less consideration to the interests of society. Meanwhile, humanbased values of postmodernism also contributed to some students of pragmatism, utilitarianism, hedonism and undisciplined doctrine. In addition, the diversity ideas of postmodernism, as well as some of the effects brought by China's reform and opening up, especially diversified culture have divided students' cultural roots on value chosen, so that the values of college students tend to diversify and few students have confused political beliefs, fuzzy ideals and beliefs. These negative effects produced in the postmodern university students warned us, to strengthen and improve college ideals and beliefs of a college education has become a neces sary and urgent task.

\section{THE REFERENCE OF STUDENT MANAGEMENT OF POSTMODERNISM}

\section{A. To innovate Student Management philosophy}

The traditional higher education has a single structure, it tends to excellence in education without paying attention to personality and creative ability and too much emphasis on students in accordance with uniform pace, a unified idea, unified action specifications with ignoring the students' abilities. Postmodernism followed the principle of diversity management in education management in college students; the students were seen as individual in the development of and to recognize the differences. The main functions of schooling are suitable for social needs in the process, to explore the potential of students according to the students at different stages of development. In addition, post-modernism emphasizes genetic differences from the perspective of management, pays attention to individual differences, students may exhibit different parties and emphasis the value of life of the individual, and the individual is as a specific target school services. Management believes the differences between individual differences can become advantages, 
which provides a considerable resource for college students' self-education, self-management, and self-service. This difference of management principles of modern education put forward questions and reflections in identity management, standardized education and management philosophy, which is a shake.

\section{B. To construct the new education management mode}

Postmodern emphasis on student diversity, pluralism, equality of educational ideas, students' richness and diversity, three-dimensional and therefore tridimensional stand out. Administrators should fully respect the students' innate unique pers onality characteristics; focus on training students' autonomy and creativity. University education managers should cultivate the autonomy and creativity as an important landmark to explore, to provide students with more opportunities to practice and competition opportunities for students to be more contact with society and life planning, promoting a real sense discussion, experiment, practice law. According to the theory of post-modern education management, education management space is not limited to campus or classroom, but includes vast variety of resources to help students to create a campus environment and atmosphere to grow through a variety of initiatives for the development of talents; education process management is not the default to the conclusion as the center, but a problemcentered and exploratory process; goal of education is no longer just cognition, but integration between knowledge and goals. It breaks the traditional mechanical, rig id management paradigm, and promotes education organizations to improve and achieve justice and equality of education.

\section{To respect teacher-student relationship}

Postmodernism pays more attention to justice and equality in the education of students in the university admin istration, emphasizing the equal dialogue between the subject of education, there is no authority, there is no repression; postmodernism believes that education is a participant manager, collaborator and demonstrator, Education Management model is not a purely logical deductive model, but combines logical deduction, interpersonal communication and infection, life penetration and environmental cues into a integrated model, which promotes a variety of ways to explore curriculu m knowledge, teaching methods should firmly oppose various forms of indoctrination, so that it become a process under the guidance of teachers, the teachers and students oppose the hegemony of knowledge, explore self-knowledge and the significance of the process; to emphasize openness, equality and dialogue, it holds that man exist as a form of cultural and biological blend of body language, advocates an open and fair dialogue that dialogue is the process to interpret how personal relationships occur, advocates equal exchanges between different understanding of the relationship. On education management and authorization, postmodernism focus on the decentralization, cooperation, communication, dialogue, respect individual differences and equality, gender equality, racial and cultural differences.

\section{To innovate Student Management Methods}

Postmodernism pay more attention to diversity in education management in Higher Education Management. Education Management approach is not unique but diverse, is not dialogue but confrontation. This shows that education management theory change from single to multiple; at the same time, diverse educational management theory is integrated: a common spirit, such as emphasizing organization, power, knowledge development and diversification, emphasizing dialogue, understanding, communication, interpretation, etc. emphasizing the management of de mocratization, decentralization, justice and the pursuit of human freedom, liberation, and the creation of value and so on. In addition, because of the acceleration of information technology and network, Western cultural thoughts flooded, to some degrees, it has an impact on the ideological soul of contemporary college students, students have a wider choice of space and accept a variety of ideas and culture, leading to ideas of students and presents values become diversity, management of university education must also enhance the relevance and effectiveness, in education management implementation, we should train students by a variety of evaluation methods, a variety of management and focus on the management of their flexibility.

\section{REFERENCES}

[1] Li Haiyan. Revelation Postmodernism current college student education management [J]. Southwest Agricultural University (Social Science Edition),2005,03:133-135.

[2] Luo Zhongxiu. Advance of College Student Education Management [J]. Hunan Taxation College, 2003,06:64-65.

[3] Zhuai Sheng, The handsome segment after the Enlightenment concept of modern education undergraduate education management "90" [J]. Theory,2011,20:173-174.

[4] Zhang YoutLi. Postmodernism and Student Management [J]. Jiangsu Higher,2012,01:127-128.

[5] Wu Hengzhong. Scientific connotation of Student Management in humanistic care [J]. Heilongjiang Higher Education Research,2012,02:63-65.

[6] Wang Yan, Wang Huan, Jun Tan. Student Management postmodernism under discussion [J]. Technological horizon, $2013,24: 50+86$.

[7] Hi Chao, Wang Jing, TAN Shujuan, Pender distant sound mechanism Student Management Innovative ideas -. Institute of Physical Education, Yunnan Agricultural University as an example [J] value engineering,2013,24:1-3.

[8] You Minhui. Revelation after modernism Analysis of University Education Management [J]. Higher Education Exploration,2006,01:47-50. 